ERRATUM

\title{
Assessing functional status using the IADL-extended scale: results from the HELIAD study - ERRATUM
}

F. Kalligerou, R. Fieo, G. P. Paraskevas, I. Zalonis, M. H. Kosmidis, M. Yannakoulia,

E. Ntanasi, E. Dardiotis, G. Hadjigeorgiou, P. Sakka, and N. Scarmeas

DOI: https://doi.org/10.1017/S1041610219001091, Published by Cambridge University Press, 10 September 2019

Key words: IADL-extended, cognition, function; erratum

The above article (Kalligerou et al., 2019) published with an incorrect reference.

The correct reference is as follows:

The Staff of the Benjamin Rose Hospital. (1959). MULTIDISCIPLINARY studies of illness in aged persons. II. A new classification of functional status in activities of daily living. Fournal of Chronic Disease, 9, $55-62$.

Furthermore, the in-text citation should read (The Staff of the Benjamin Rose Hospital, 1959).

The publisher apologizes for the error.

\section{Reference}

Kalligerou, F., Fieo, R., Paraskevas, G. P., Zalonis, I., Kosmidis, M. H., Yannakoulia, M., Ntanasi, E., Dardiotis, E., Hadjigeorgiou, G., Sakka, P. and Scarmeas, N. (2019). Assessing functional status using the IADL-extended scale: results from the HELIAD study. International Psychogeriatrics, doi: 10.1017/S1041610219001091. 